CLINICAL STUDY

\title{
Spectrum of metabolic dysfunction in relationship with hyperandrogenemia in obese adolescent girls with polycystic ovary syndrome
}

\author{
Ramin Alemzadeh ${ }^{1,2}$, Jessica Kichler ${ }^{2}$ and Mariaelena Calhoun ${ }^{1}$ \\ ${ }^{1}$ Section of Pediatric Endocrinology and Metabolism, Department of Pediatrics, Medical College of Wisconsin, 8701 Watertown Plank Road, Milwaukee, \\ Wisconsin 53226, USA and ${ }^{2}$ Diabetes Center, Children's Hospital of Wisconsin, Milwaukee, Wisconsin 53201, USA \\ (Correspondence should be addressed to R Alemzadeh; Email: ralemzad@mcw.edu)
}

\begin{abstract}
Objective: Polycystic ovary syndrome (PCOS) in adult women is associated with increased risk of metabolic syndrome (MS) and atherosclerosis. We evaluated the spectrum of metabolic dysfunction in relationship with hyperandrogenemia (HA) in adolescent girls with PCOS.

Materials and methods: Ovulatory function, acne, hirsutism (HS), body mass index (BMI), body composition, fasting lipids, glucose, insulin, free testosterone (FT), high-sensitivity C-reactive protein (hs-CRP), and HbAlc were evaluated in 103 girls. The homeostatic assessment model equations (HOMA-IR and HOMA-\%B) were used for determination of insulin resistance and $\beta$-cell function respectively.

Results: The oligo-ovulation (Oligo) + HA + HS $(n=44)$, Oligo + HA $(n=28)$, and Oligo + HS $(n=31)$ phenotypes had similar BMI. However, hyperandrogenemic phenotypes had higher prevalence of acanthosis nigricans $(\mathrm{AN})$ and acne $(P<0.01)$ and higher insulin, HOMA-IR, HOMA-\%B, HbA1c, and hs-CRP levels than Oligo + HS group $(P<0.01)$. Serum FT was correlated with HOMA-IR $(r=0.38$, $P<0.01)$, HOMA-\%B $(r=0.49, P<0.01)$, hs-CRP $(r=0.42, P<0.01)$, AN $(r=0.39, P<0.01)$, and HbA1c $(r=0.27, P<0.01)$. Furthermore, 34\% of girls met diagnostic criteria for MS displaying higher BMI, FT, HOMA-\%B, HOMA-IR, hs-CRP, and HbA1c than subjects without MS $(P<0.01)$. Using combined HOMA-IR $\geq 4.0$ and hs-CRP $>3.0$ cut-off values, $71.4 \%$ of MS versus $23.5 \%$ non-MS group were considered at risk of diabetes and atherosclerosis $(P<0.0001)$.

Conclusions: Hyperandrogenemic PCOS phenotypes have greatest degree of insulin resistance and inflammation. The use of insulin resistance and inflammatory markers may help identify adolescent girls with PCOS at risk of cardiometabolic syndrome.
\end{abstract}

European Journal of Endocrinology 162 1093-1099

\section{Introduction}

Polycystic ovary syndrome (PCOS) is a common endocrine disorder, occurring in $\sim 6 \%$ of women at reproductive age $(1,2)$. This endocrinopathy is characterized by oligomenorrhea and/or anovulation, clinical and/or biochemical hyperandrogenemia (HA) with or without ultrasonographic evidence of polycystic ovaries after exclusion of other disorders such as hyperprolactinemia, thyroid dysfunction, and nonclassical adrenal hyperplasia $(3,4)$. This hyperandrogenemic state with chronic ovulatory dysfunction is a heterogeneous disorder with a broad spectrum of phenotypes (5). These clinical phenotypes are defined by their clinical, hormonal, metabolic, and reproductive features of PCOS in adult women and adolescents $(5,6)$. PCOS is accompanied by an enhanced risk of insulin resistance and hyperinsulinemia, type 2 diabetes mellitus (T2DM), dyslipidemia, and atherosclerosis $(7,8)$, implying that diagnosis of PCOS in young women increases the likelihood of life-long risks of menstrual dysfunction, infertility, T2DM, and premature heart disease (7-9).

Insulin directly stimulates ovarian androgen production through the stimulation of $17 \alpha$-hydroxylase activity at the ovarian theca and reduces 17,20-lyase responsiveness in women with PCOS $(10,11)$. Similarly, hyperinsulinemia has been shown to be associated with excess adrenal androgen synthesis $(11,12)$. Recent studies have not demonstrated any effect of insulin on adrenal androgen production $(12,13)$.

The diagnosis of PCOS might be difficult since some features of the syndrome are physiologic during adolescence (14). Almost $60 \%$ of the menstrual cycles 
are anovulatory, and enlarged ovaries may be common findings, representing features of the physiologic processes of maturation during the first few years after menarche $(15,16)$. During puberty, there is a physiologic increase in insulin resistance, and circulating insulin and androgen levels, resulting from the increase in GH levels, but a reduction in sex hormonebinding globulin levels $(17,18)$. Accurate diagnosis of PCOS may be difficult using current criteria, which might overestimate the diagnosis and interfere with the clinical management of adolescent oligomenorrhea. Among postmenarchal obese girls who subsequently develop glucose intolerance, PCOS has become a prevalent cause of HA, defined as free testosterone (FT) $>35 \mathrm{pmol} / \mathrm{l}(15,16)$ and ovulatory dysfunction. In adult women, three clinical phenotypes of PCOS, with varying degrees of metabolic dysfunction influencing the development of HA and hirsutism (HS), have been described (5). We evaluated the spectrum and prevalence of metabolic dysfunction in relationship with $\mathrm{HA}$, indices of insulin resistance and low-intensity inflammation in a group of adolescent females with three PCOS phenotypes.

\section{Materials and methods}

\section{Subjects}

One hundred and three female adolescents (aged 13.2-19.9 years) who met the criteria for PCOS and obesity (BMI $>95$ th percentile for age) were included in the study. All subjects were evaluated at the Children's Hospital of Wisconsin (CHW; affiliated with the Medical College of Wisconsin) Endocrine Clinic for oligomenorrhea or secondary amenorrhea between September 2005 and February 2008. Race/ethnicity was selfassigned: Caucasian (C, $n=56 ; 54.4 \%)$, Mexican American (Hispanic (H), $n=26 ; 25.2 \%$ ), and African American (AA, $n=21 ; 20.4 \%$ ). All patients were postmenarchal for a minimum of 2 years. Individuals with hyperprolactinemia, hypo- or hyperthyroidism, congenital adrenal hyperplasia (17-hydroxyprogesterone $(17-\mathrm{OHP})<200 \mathrm{ng} / \mathrm{ml}(6.0 \mathrm{nmol} / \mathrm{l}))(19)$, Cushing's syndrome, androgen-secreting tumors, and primary or secondary ovarian failure, and on hormonal treatment for at least 3 months prior to their evaluation were excluded (2). In compliance with the recommendations of the Declaration of Helsinki, the CHW Institutional Review Board approved the retrospective review of participants' clinical charts; therefore, informed consent was waived.

\section{Methods}

Clinical evaluation Patients and/or their guardians completed a standard questionnaire detailing their menstrual history, HS, acne, gynecologic and obstetric history, medications, self-declared ethnicity, and family history of PCOS and T2DM diagnosis. A positive family history of HA was defined as a history of PCOS or of HS and oligomenorrhea in the first-degree female relatives of the patient. Oligomenorrhea was defined as menstrual periods occurring at intervals of $>35$ days, with only four to nine periods in a year. Amenorrhea was defined as complete absence of menstruation for 6 months or more, after having established menstrual bleeding for a minimum of 2 years. All subjects were evaluated during the follicular phase of their cycle.

On physical examination, height, weight, BMI, blood pressure (BP), and body composition analysis by bioelectrical impedance (BIA) (TANITA-TBF-410, TANITA Corporation of America Inc., Arlington Heights, IL, USA) (20) were obtained. The presence of terminal hair growth in a male-like pattern was scored using Ferriman-Gallwey (FG) method (21); HS was defined as a score $>8$ (16). The presence or absence of acanthosis nigricans (AN) and acne was noted, but not quantified. Two well-trained clinicians determined pubertal maturation (Tanner stage). Fasting serum samples were obtained for glucose, insulin, and lipid profile, high-sensitivity C-reactive protein (hs-CRP) along with HbA1c, LH, FSH, DHEAS, 17-OHP, androstenedione, total testosterone, and FT. Subjects were classified into three phenotype groups: Oligo + HA + HS, Oligo + HA, and Oligo + HS as previously described in adolescents and adults $(5,6)$.

Laboratory studies and calculations All blood samples were obtained between 0800 and $1100 \mathrm{~h}$. Serum glucose was measured by an autoanalyzer (Orthodiagnostics Fusion 5.1, Ortho-Diagnostics, Rochester, NY, USA). The hs-CRP assays were carried out at Quest Diagnostics (San Jose, CA, USA) using a polystyrene particle-enhanced immunonephelometric method (Dade Behring BNII). The detection limit of this assay was $0.20 \mathrm{mg} / \mathrm{l}$ with measuring range of $0.18-1150 \mathrm{mg} / \mathrm{l}$ with intra-assay and inter-assay coefficients of variance of 2.65 and $3.6 \%$ respectively. The hs-CRP value $>3.0 \mathrm{mg} / \mathrm{l}$ was considered as an index of high cardiovascular risk (22), but hs-CRP values $>10 \mathrm{mg} / \mathrm{l}$ were excluded to avoid influence of acute infection. HbAlc was determined by the Bayer DCA (Bayer Diagnostics Inc.) 2000 instrument (nondiabetic range of 4.5-5.7\%).

Fasting serum insulin was measured by Nichols RIA (Nichols Institute, San Clemente, CA, USA) with intra-assay and inter-assay coefficients of variation (CV) of $2.4-6.3$ and $5.2-13.0 \%$ respectively. The homeostatic model assessment estimates for insulin resistance (HOMA-IR) and percent $\beta$-cell function (HOMA-\%B) were calculated as previously described (23): HOMA-IR $=($ blood glucose $(\mathrm{mmol} / \mathrm{l}) \times$ insulin $(\mu \mathrm{U} / \mathrm{ml})) / 22.5$ and HOMA- $\% \mathrm{~B}=20 \times$ insulin $(\mu \mathrm{U} / \mathrm{ml}) /$ (glucose $(\mathrm{mmol} / \mathrm{l})-3.5)$. A cut-off HOMA-IR value 
$\geq 4.0 \mathrm{~mol} \mu \mathrm{U} / \mathrm{ml}$ ( $>95$ th percentile (HOMA-IR =3.99)) was used to define insulin-resistant state $(24,25)$.

Serum LH and FSH concentrations were determined by chemiluminescent (Johnson \& Johnson S.p.A-Otho Clinical Inc., Rochester, NY, USA). Serum DHEAS level was determined by a chemiluminescent assay (Quest Diagnostics) with intra-assay and inter-assay CV of $6.2-9.6$ and $7.3-11.3 \%$ respectively. Serum 17-OHP concentrations were determined by highpressure liquid chromatography-mass spectrometry (HTLC-MS) (Quest Diagnostics) with relative s.D. (RSD) range of $4.8-14.0 \%$. Serum androstenedione concentrations were determined by HTLC-MS (Quest Diagnostics) with RSD range of 4.3-14.0\%. Total testosterone level was determined by HTLC-MS (Quest Diagnostics) with RSD range of 7.1-10.8\%. Serum FT was determined by an equilibrium dialysis method (Quest Diagnostics) with intra-assay and inter-assay CV of 4.5-11.8 and 4.2-11.3\% respectively.

Total cholesterol, high-density lipoprotein cholesterol (HDL-C), and triglycerides (TGs) were determined by colorimetric methods (Beckman spectrophotometer, Fullerton, CA, USA). Low-density lipoprotein cholesterol (LDL-C) was calculated using Friedewald's equation (26).

BP measurements were taken twice with the patient in sitting position. Elevated systolic or diastolic pressure was defined as a value above the 95 th percentile for age and gender (27).
Modified National Cholesterol Education Program criteria (28) for diagnosis of metabolic syndrome (MS) were defined as the presence of three or more of the following: age-adjusted BMI > 95th percentile, age-adjusted systolic or diastolic BP $>90$ th percentile, age-adjusted TG $>$ 90th percentile, age-adjusted HDL-C $<5$ th percentile, and impaired fasting glucose $>5.6 \mathrm{mmol} / \mathrm{l}$.

\section{Statistical analysis}

Statistical analyses were carried out using SPSS (version 14.0). Data are expressed as mean \pm s.D. unless otherwise specified. Body mass index (BMI) values were converted into SDS, which were normalized for age and gender based on 2000 Center for Disease control (CDC) growth charts. The natural logarithmic transformation of the variables was used in the correlation and regression analyses when they were found to be skewed. Differences between PCOS + MS and PCOS only groups were estimated using unpaired Student's $t$-tests. Then, the differences among PCOS phenotypes were estimated by one-way ANOVA; Bonferroni's post hoc test was applied whenever appropriate. The $\chi^{2}$ analyses were used to compare prevalence of AN, acne, oligomenorrhea, and amenorrhea in PCOS subgroups. Spearman's correlations were performed to examine the associations between FT and HOMA-IR, HOMA-\%B, HbA1c, hs-CRP and TG, while controlling for fat mass (FM). Bivariate correlations and

Table 1 Comparison of clinical and biochemical characteristics among adolescent polycystic ovary syndrome phenotypes.

\begin{tabular}{|c|c|c|c|c|c|}
\hline Characteristics & All & Oligo $+\mathrm{HA}+\mathrm{HS}$ & Oligo + HA & Oligo + HS & $P$ \\
\hline Number (\%) & 103 & $44(42.7)$ & $28(27.2)$ & $31(30.1)$ & NS \\
\hline Age (years) & $15.5 \pm 1.3$ & $15.5 \pm 1.2$ & $15.6 \pm 1.6$ & $15.3 \pm 1.1$ & NS \\
\hline \multicolumn{6}{|l|}{ Race/ethnicity } \\
\hline Caucasian (\%) & $56(54.4)$ & $27(61.4)$ & $14(50.0)$ & $15(48.4)$ & NS \\
\hline Hispanics (\%) & $26(25.2)$ & $7(15.9)$ & $8(28.6)$ & $11(35.5)$ & $<0.01^{\dagger}$ \\
\hline African Americans (\%) & $21(20.4)$ & $10(22.7)$ & $6(21.4)$ & $5(16.1)$ & NS \\
\hline BMl $\left(\mathrm{kg} / \mathrm{m}^{2}\right)$ & $36.2 \pm 8.4$ & $37.8 \pm 9.4$ & $36.9 \pm 7.9$ & $33.6 \pm 6.8$ & NS \\
\hline BMI SDS & $2.12 \pm 0.47$ & $2.20 \pm 0.42$ & $2.16 \pm 0.48$ & $1.98 \pm 0.52$ & NS \\
\hline Acanthosis nigricans present (\%) & $63(61.2)$ & $32(72.7)$ & $21(75.0)$ & $10(32.3)$ & $<0.01^{\ddagger}$ \\
\hline Acne present (\%) & $34(33.1)$ & $18(40.9)$ & $13(46.4)$ & $6(19.4)$ & $<0.01^{\ddagger}$ \\
\hline FG score & $8.9 \pm 3.3$ & $11.2 \pm 2.5$ & $4.9 \pm 0.9$ & $9.2 \pm 2.2$ & $<0.0001$ \\
\hline Free testosterone (pmol/l) & $41.8 \pm 17.1$ & $48.1 \pm 13.7$ & $48.0 \pm 17.6$ & $26.2 \pm 5.7$ & $<0.001^{\| \prime}$ \\
\hline Testosterone $(\mathrm{nmol} / \mathrm{l})$ & $2.4 \pm 0.8$ & $2.6 \pm 0.8$ & $2.6 \pm 0.7$ & $1.8 \pm 0.3$ & $<0.001^{\|}$ \\
\hline DHEAS $(\mu \mathrm{mol} / \mathrm{l})$ & $5.9 \pm 3.3$ & $6.8 \pm 3.9$ & $6.5 \pm 3.1$ & $4.5 \pm 1.8$ & $<0.01^{\ddagger}$ \\
\hline 17-Hydroxyprogesterone $(\mathrm{nmol} / \mathrm{l})$ & $3.4 \pm 1.6$ & $3.6 \pm 1.6$ & $3.3 \pm 1.7$ & $3.3 \pm 1.6$ & NS \\
\hline Androstenedione $(\mathrm{nmol} / \mathrm{l})$ & $7.7 \pm 3.3$ & $8.1 \pm 3.2$ & $7.2 \pm 3.0$ & $7.3 \pm 3.4$ & NS \\
\hline Fasting glucose $(\mathrm{mmol} / \mathrm{l})$ & $4.9 \pm 0.4$ & $4.8 \pm 0.4$ & $5.1 \pm 0.4$ & $4.9 \pm 0.3$ & NS \\
\hline Fasting insulin (pmol/l) & $181.5 \pm 99.6$ & $205.1 \pm 110.2$ & $201.8 \pm 83.5$ & $132.5 \pm 80.1$ & $<0.01^{\ddagger}$ \\
\hline HOMA-IR $(\mathrm{mol} \mu \mathrm{U} / \mathrm{ml})$ & $6.6 \pm 3.7$ & $7.3 \pm 3.8$ & $7.6 \pm 3.4$ & $4.8 \pm 3.2$ & $<0.01^{\ddagger}$ \\
\hline HOMA- $\beta$-cell (\%) & $495.8 \pm 406.9$ & $613.9 \pm 499.4$ & $484.2 \pm 371.9$ & $329.7 \pm 184.8$ & $<0.01^{\S}$ \\
\hline $\mathrm{HbA1c}(\%)$ & $5.2 \pm 0.4$ & $5.2 \pm 0.3$ & $5.3 \pm 0.4$ & $5.0 \pm 0.3$ & $<0.01^{\ddagger}$ \\
\hline $\mathrm{hs}-\mathrm{CRP}(\mathrm{mg} / \mathrm{l})$ & $3.0 \pm 1.5$ & $3.2 \pm 1.4$ & $3.3 \pm 1.5$ & $2.4 \pm 1.3$ & $<0.025^{\star}$ \\
\hline Triglycerides $(\mathrm{mmol} / \mathrm{l})$ & $1.6 \pm 0.9$ & $1.7 \pm 1.0$ & $1.6 \pm 1.0$ & $1.4 \pm 0.9$ & NS \\
\hline Cholesterol (mmol/l) & $4.5 \pm 1.0$ & $4.5 \pm 1.1$ & $4.5 \pm 0.9$ & $4.4 \pm 1.0$ & NS \\
\hline
\end{tabular}

${ }^{\star} P<0.025$, Oligo $+\mathrm{HA}+\mathrm{HS}$ and Oligo $+\mathrm{HA}$ groups versus Oligo $+\mathrm{HS}$ group. ${ }^{\dagger} P<0.01$, for comparison of Oligo $+\mathrm{HA}+\mathrm{HS}$ group versus Oligo $+\mathrm{HA}$ and Oligo $+\mathrm{HS}$ groups. ${ }^{\ddagger} P<0.01$, for comparison of Oligo $+\mathrm{HA}+\mathrm{HS}$ and Oligo $+\mathrm{HA}$ groups versus Oligo $+\mathrm{HS}$ group. ${ }^{\S} P<0.01$, for comparison of Oligo $+\mathrm{HA}+\mathrm{HS}$ group versus Oligo $+\mathrm{HS}$ group. " $P<0.001$, for comparison of Oligo $+\mathrm{HA}+\mathrm{HS}$ and Oligo $+\mathrm{HA}$ groups versus Oligo $+\mathrm{HS}$ group. ${ }^{\mathrm{I}} P<0.0001$, for comparison of Oligo $+\mathrm{HA}+\mathrm{HS}$ and Oligo + HS groups versus Oligo + HA group. 
a stepwise regression analysis between potential predictor variables and the dependent variable (FT) were performed while controlling for the demographic covariates of the entire cohort. $P<0.05$ was considered significant.

\section{Results}

Table 1 summarizes the clinical and biochemical characteristics of entire cohort of obese adolescent girls with oligo-ovulation and three groups of PCOS phenotypes. Three groups were similar in age, BMI, BMI SDS, FM, fat-free mass, and total body water. While Caucasian and African American subjects were observed to have similar representations of three phenotypes, the percentages of Hispanic girls with Oligo + HA and Oligo + HS were higher than those with Oligo + HA + HS. Also, hyperandrogenemic groups $(\mathrm{FT}>35 \mathrm{pmol} / \mathrm{l})$ had higher frequencies of acne and AN than the Oligo + HS group. However, the frequencies of amenorrhea were not statistically different among three phenotypes (36.4 vs 35.7 vs $22.6 \%, P=\mathrm{NS}$ ).

While there were no differences in LH, FSH, LH:FSH ratio, 17-OHP, and androstenedione values among groups, serum testosterone, FT, and DHEAS were higher in Oligo $+\mathrm{HA}+\mathrm{HS}$ and Oligo $+\mathrm{HA}$ compared with Oligo + HS $(P<0.01)$. There were no significant differences in hormonal and metabolic parameters in Oligo + HA + HS versus Oligo + HA. However, the hyperandrogenemic groups had higher insulin, HOMA-IR,
HbA1c, and hs-CRP. All three groups displayed marked hyperinsulinemia with both hyperandrogenemic groups displaying similar $\beta$-cell function values; however, HOMA-\%B values were found to be only higher in Oligo + HS + HA group compared with Oligo + HS group. Furthermore, three groups displayed similar fasting lipid profiles (data not shown).

Table 2 summarizes the clinical and biochemical characteristics of females stratified into PCOS + MS and PCOS only subgroups. In our cohort, $34 \%$ of females met diagnostic criteria for MS displaying higher BMI, FT, HOMA-\%B, HOMA-IR, hs-CRP, and HbAlc and frequency of $\mathrm{AN}$ than PCOS only subjects $(P<0.05)$ without significant differences in relationship with other androgens (data not shown). There were no differences between the groups in relationship with positive family history of T2DM and PCOS, frequencies of acne, amenorrhea ( 40 vs $27.9 \%, P=\mathrm{NS}$ ), and FG score. A cut-off HOMA-IR $\geq 4.0$ identified $77.4 \%$ of the entire cohort as insulin resistant with $94.3 \%$ of PCOS + MS compared with $72.1 \%$ of PCOS only groups as insulin resistant $(P<0.01)$. A cut-off hs-CRP $>3.0$ identified $41.7 \%$ of entire cohort with low-grade chronic inflammation with $74.3 \%$ of PCOS + MS group compared with $25.0 \%$ of PCOS only group at increased risk of atherosclerosis $(P<0.0001)$. Using combined HOMA-IR $\geq 4.0$ and hs-CRP $>3.0$ cut-off values, $71.4 \%$ of $\mathrm{PCOS}+\mathrm{MS}$ compared with $23.5 \%$ PCOS only group were deemed at risk of diabetes and atherosclerosis $(P<0.0001)$.

Table 2 The comparison of polycystic ovary syndrome (PCOS) + metabolic syndrome (MS) and PCOS only subgroups.

\begin{tabular}{|c|c|c|c|}
\hline Characteristics & $\mathrm{PCOS}+\mathrm{MS}$ & PCOS only & $\boldsymbol{P}$ \\
\hline Number (\%) & $35(34.0)$ & $68(66)$ & NA \\
\hline Age (years) & $15.5 \pm 1.3$ & $15.4 \pm 1.3$ & NS \\
\hline \multicolumn{4}{|l|}{ Race/ethnicity } \\
\hline Caucasian (\%) & $16(45.7)$ & $40(58.8)$ & NS \\
\hline Hispanics (\%) & $10(28.6)$ & $16(23.5)$ & NS \\
\hline African Americans (\%) & $9(25.7)$ & $12(17.7)$ & NS \\
\hline BMI SDS & $2.30 \pm 0.47^{\dagger}$ & $2.04 \pm 0.46$ & $<0.01$ \\
\hline $\mathrm{FM}(\mathrm{kg})$ & $49.7 \pm 18.3^{\dagger}$ & $39.4 \pm 14.9$ & $<0.01$ \\
\hline Acanthosis nigricans present (\%) & $25(\overline{71} .4)^{\star}$ & $38(55.9)$ & $<0.05$ \\
\hline Acne present (\%) & $16(45.7)$ & $21(30.9)$ & NS \\
\hline FG score & $9.7 \pm 3.6$ & $8.5 \pm 3.1$ & NS \\
\hline Amenorrhea (\%) & $14(40.0 \%)$ & $19(27.9 \%)$ & NS \\
\hline Oligomenorrhea (\%) & $21(60 \%)$ & $49(72.1 \%)$ & NS \\
\hline Systolic BP & $132.4 \pm 16.1^{\dagger}$ & $123.5 \pm 11.3$ & $<0.01$ \\
\hline Diastolic BP & $72.1 \pm 9.3^{\dagger}$ & $67.1 \pm 8.5$ & $<0.01$ \\
\hline Free testosterone $(\mathrm{pmol} / \mathrm{l})$ & $48.6 \pm 17.7^{\dagger}$ & $38.5 \pm 15.9$ & $<0.01$ \\
\hline Fasting glucose $(\mathrm{mmol} / \mathrm{l})$ & $4.9 \pm 0.5$ & $4.9 \pm 0.4$ & NS \\
\hline Fasting insulin (pmol/l) & $226.8 \pm 115.2^{\ddagger}$ & $158.2 \pm 82.0$ & $<0.001$ \\
\hline HOMA-IR (mol $\mu \mathrm{U} / \mathrm{ml})$ & $8.2 \pm 4.1^{\dagger}$ & $5.8 \pm 3.2$ & $<0.01$ \\
\hline HOMA- $\beta$-cell $(\%)$ & $638.2 \pm 475.1^{\dagger}$ & $422.5 \pm 348.5$ & $<0.01$ \\
\hline $\mathrm{HbA} 1 \mathrm{c}(\%)$ & $5.3 \pm 0.4^{\dagger}$ & $5.1 \pm 0.3$ & $<0.01$ \\
\hline hs-CRP (mg/l) & $3.8 \pm 1.6^{\S}$ & $2.6 \pm 1.2$ & $<0.0001$ \\
\hline Triglycerides (mmol/l) & $2.3 \pm 1.0^{\S}$ & $1.2 \pm 0.6$ & $<0.0001$ \\
\hline Cholesterol $(\mathrm{mmol} / \mathrm{l})$ & $4.9 \pm 1.0^{\dagger}$ & $4.3 \pm 1.0$ & $<0.01$ \\
\hline Cholesterol:HDL-C & $5.7 \pm 1.4^{\S}$ & $4.1 \pm 1.2$ & $<0.0001$ \\
\hline Triglycerides:HDL-C & $2.7 \pm 1.3^{\S}$ & $1.2 \pm 0.8$ & $<0.0001$ \\
\hline
\end{tabular}

${ }^{*} P<0.05,{ }^{\dagger} P<0.01,{ }^{\ddagger} P<0.001$, and ${ }^{\S} P<0.0001$; not applicable (NA) and not significant (NS). 
Table 3 Bivariate correlations between predictor and dependent variables, while controlling for covariates in the entire cohort.

\begin{tabular}{|c|c|c|c|c|c|c|c|}
\hline & FT & AN & TG:HDL-C & HOMA-IR & HОМА-\%В & hs-CRP & HbA1c \\
\hline $\begin{array}{l}\text { FT (pmol/l) } \\
\text { Acanthosis nigricans } \\
\text { TG:HDL-C } \\
\text { HOMA-IR (mol } \mu \mathrm{U} / \mathrm{ml}) \\
\text { HOMA- } \beta \text {-cell }(\%) \\
\text { hs-CRP }(\mathrm{mg} / \mathrm{l}) \\
\text { HbA1c }(\%)\end{array}$ & 1.0 & $\begin{array}{l}0.33^{\dagger} \\
1.0\end{array}$ & $\begin{array}{l}0.18 \\
0.13 \\
1.0\end{array}$ & $\begin{array}{l}0.32^{\dagger} \\
0.43^{\dagger} \\
0.28^{\dagger} \\
1.0\end{array}$ & $\begin{array}{l}0.44^{\dagger} \\
0.30^{\dagger} \\
0.29^{\dagger} \\
0.65^{\dagger} \\
1.0\end{array}$ & $\begin{array}{l}0.36^{\dagger} \\
0.41^{\dagger} \\
0.54^{\dagger} \\
0.42^{\dagger} \\
0.41^{\dagger} \\
1.0\end{array}$ & $\begin{array}{l}0.24^{\star} \\
0.45^{\dagger} \\
0.08^{\dagger} \\
0.33^{\dagger} \\
0.14 \\
0.25^{\star} \\
1.0\end{array}$ \\
\hline
\end{tabular}

${ }^{*} P<0.05,{ }^{\dagger} P<0.01$.

Correlation analyses were conducted with all the potential predictor variables (HOMA-IR, HOMA-\%B, hs-CRP, HbA1c, TG, TG:HDL-C, AN, DHEAS, and Chol:HDL) and the dependent variable (FT). Serum FT was correlated with HOMA-IR, HOMA-\%B, hs-CRP, HbA1c, TG:HDL-C, and AN. Correlation analyses were then conducted with these predictor and/or the dependent variables and demographic variables (ethnicity, BMI, FM, and age). Serum FT was related to BMI and FM. BMI and ethnicity were correlated with HOMA-IR, HOMA-\%B, hs-CRP, HbAlc, and AN. FM was correlated with HOMA-IR, HOMA-\%B, hs-CRP, TG:HDL-C, and AN (data not shown).

Table 3 summarizes the partial correlations for the related predictor variables (HOMA-IR, HOMA-\%B, hs-CRP, HbA1c, TG:HDL-C, and AN) and the dependent variable (FT), while controlling for the covariates (ethnicity, BMI, and FM) within the entire cohort. Serum FT remained correlated with AN, HOMA-IR, HOMA-\%B, hs-CRP, and HbA1c, but not with TG:HDL-C.

Using a stepwise regression analysis, the covariates were entered first (ethnicity, BMI, and FM), and the predictor variables that were significantly related to the dependent variable (FT) were entered next (AN, HOMA-IR, HOMA-\%B, hs-CRP, and HbAlc). BMI accounted for a significant proportion of the variance $(\beta=0.26, t=2.73, P<0.01)$. HOMA-\%B and AN were the only predictor variables that emerged with significant main effects for FT $(\beta=0.48, t=4.82, P<0.01$ and $\beta=0.21, t=2.09, P<0.01$ respectively).

\section{Discussion}

In our study, subjects with hyperandrogenemic phenotypes displayed the greatest degree of hyperinsulinemia, $\beta$-cell function, and chronic inflammation, whereas females with HS but no evident HA had mildest degrees of androgen elevation, hyperinsulinemia, insulin resistance, and inflammation. Females with only HA seemed to have intermediate degrees of $\mathrm{HA}$ and metabolic dysfunction. The three PCOS phenotypes displayed varying degrees of metabolic dysfunction.

The rise in serum androgens is accompanied by excess insulin secretion, suggesting that insulin directly stimulates ovarian androgen production as previously shown (29). The degree of hyperinsulinemia does not seem to be directly correlated with the development of HS. The observed difference in the degree of HS (FG score) between hirsute females with and without HA implies that higher androgen and insulin levels stimulate hair growth $(30,31)$. However, higher activity of androgen receptors has been associated with preferential expression of androgen receptors, implying that genetic and epigenetic changes may be involved in the pathogenesis of PCOS (32). In this cohort, degree of hyperinsulinemia and insulin resistance determined the severity of the phenotype with HS only demonstrating lesser $\beta$-cell function and insulin resistance than hyperandrogenemic phenotypes (4). While there was no significant difference in body adiposity among the groups, hyperandrogenemic groups had higher prevalence of acne and AN than hirsute group without excess androgens. The frequencies of oligomenorrhea and amenorrhea among three phenotypes were similar to those previously reported in women and adolescents $(6,33)$. Although higher prevalence of amenorrhea has been associated with a greater degree of metabolic dysfunction (34), this is likely due to increased body adiposity, and not insulin resistance, across all phenotypes $(35,36)$. In our cohort, frequency of amenorrhea was not higher in PCOS + MS groups compared with PCOS only group, despite higher insulin resistance and androgen levels in the former. Indeed, biochemical HA did not correlate consistently with this menstrual disorder, and is likely due to variable tissue-specific end-organ sensitivity to androgens (32).

HA has been identified as an important risk factor for MS and dyslipidemias in premenopausal women and adolescents $(5,6,37)$. According to the HOMA, $77.4 \%$ of our subjects were insulin resistant which is higher than observed by Valerio et al. (41.2\%) in obese children and adolescents (38); yet, only one-third of our cohort met diagnostic criteria for MS (28) compared with 53\% of a group of obese adolescents with PCOS (39). It has been suggested that the metabolic impairment is not evident to the same degree in all PCOS phenotypes in adolescent females (6). While obesity is the most common cause of insulin resistance and dyslipidemias 
(40), the metabolic differences cannot be explained by the degree of obesity alone. In our study, HA was found to be an independent risk factor for MS as previously reported by Coviello et al. (41).

It has been reported that HA is an important risk factor for the development of dyslipidemia, especially low HDL-C and high cholesterol and TG levels $(6,42)$. Treatment of PCOS women with antiandrogen flutamide reduced total and LDL-C and increased HDL-C (43). While our study found no relationship between FT and lipid profile indices after correcting for ethnicity, BMI, and FM, the positive relationship between FT and hs-CRP implies that androgens contribute to lowintensity inflammatory state and development of MS (44). The degree of obesity and threshold in the degree of low-intensity inflammation, as measured by hs-CRP, appear to set the ground for the development of dyslipidemias and atherosclerosis $(22,45)$. In our study, about one-third of the subjects displayed evidence of chronic inflammation (46) with almost $75 \%$ of subjects with MS at high risk of atherosclerosis and $71.4 \%$ at risk of both diabetes and atherosclerosis. These findings suggest that obesity and HA, and not insulin resistance, are the major determinants of chronic inflammation and risk of atherosclerosis in adolescents with PCOS (47). The use of an inflammation marker may help identify high-risk females with PCOS.

Limitations to this study include retrospective design, relative under-representation of African American and Hispanic subjects, and lack of oral glucose tolerance data to assess glucose homeostasis and $\beta$-cell function in relationship with androgen levels and lipid profile. Also, the accuracy of BIA for the assessment of body composition has been questioned because of larger errors in individual estimates of body fat compared with dual-energy x-ray absorptiometry (DXA) method (44). However, BIA has been deemed accurate for assessing body composition in large groups of normal-weight or obese pediatric subjects compared with DXA (20). Another limitation to the study is that there were no age- and sex-matched normal-weight and obese controls for each racial/ethnic group. Inclusion of adolescent females without PCOS may have yielded stronger results evaluating the degrees of metabolic dysfunction in relationship with androgen levels when subgroups of the sample were analyzed.

In conclusion, hyperandrogenemic PCOS phenotypes have greatest degree of hyperinsulinemia, insulin resistance, and inflammation. The screening evaluation of insulin resistance and inflammation markers may identify hyperandrogenemic PCOS patients at risk of developing diabetes and atherosclerosis.

\section{Declaration of interest}

The authors declare that there is no conflict of interest that could be perceived as prejudicing the impartiality of the research reported.

\section{Funding}

This research did not receive any specific grant from any funding agency in the public, commercial or not-for-profit sector.

\section{Acknowledgements}

Presented at 91st Annual Meeting of the Endocrine Society, Washington, DC, June 9-13, 2009.

\section{References}

1 Diamanti-Kandarakis E, Kouli CR, Bergiele AT, Filandra FA, Tsianateli TC, Spina GG, Zapanti ED \& Bartziz MI. A survey of the polycystic ovary syndrome in the Greek island of Lesbos: hormonal and metabolic profile. Journal of Clinical Endocrinology and Metabolism 199984 4006-4011.

2 Azziz R, Woods KS, Reyna R, Key TJ, Knochenhauer ES \& Yildiz BO. The prevalence and features of the polycystic ovary syndrome in an unselected population. Journal of Clinical Endocrinology and Metabolism 200489 2745-2749.

3 The Rotterdam ESHRE/ASRM-Sponsored PCOS Consensus Workshop Group. Revised 2003 consensus on diagnostic criteria and long-term health risks related to polycystic ovary syndrome. Fertility and Sterility 200481 19-25.

4 Diamanti-Kandarakis E \& Panidis D. Unravelling the pheotypic map of polycystic ovaries syndrome (PCOS): a prospective study of 634 women with PCOS. Clinical Endocrinology 200767 735-742.

5 Chang WY, Knochenhauer ES, Bartolucci AA \& Azziz R. Phenotypic spectrum of polycystic ovary syndrome: clinical and biochemical characterization of the three major clinical subgroups. Fertility and Sterility 200583 1717-1723.

6 Fruzzetti F, Perini D, Lazzarini V, Parrini D \& Genazzani AR. Adolescent girls with polycystic ovary syndrome showing different phenotypes have different metabolic profile associated with increasing androgen. Fertility and Sterility 200992 626-634.

7 Ehrmann DA. Polycystic ovary syndrome. New England Journal of Medicine 2005352 1223-1236.

8 Hardiman O, Pillay OS \& Atiomo W. Polycystic ovary syndrome and endometrial carcinoma. Lancet 2003361 1810-1812.

9 Legro RS. Polycystic ovary syndrome and cardiovascular disease: a premature association? Endocrine Reviews 200324 302-312.

10 Falcone T, Finegood DT, Fantus IG \& Morris D. Androgen response to endogenous insulin secretion during the frequently sampled intravenous glucose tolerance test in normal and hyperandrogenic women. Journal of Clinical Endocrinology and Metabolism 199071 $1653-1657$.

11 Diamond MP, Grainger DA \& Laudaro AJ. Effect of acute physiological elevations of insulin on circulating androgen levels in normal women. Journal of Clinical Endocrinology and Metabolism 199172 883-887.

12 Farah-Eways L, Reyna R, Knochenhauer ES, Bartolucci AA \& Azziz R. Glucose action and adrenocortical biosynthesis in women with polycystic ovary syndrome. Fertility and Sterility $2004 \mathbf{8 1}$ 120-125.

13 Kaufman RP, Baker VM, DiMarino P \& Castracane VD. Hyperinsulinemia and circulating dehydroepiandrosterone sulfate in while and Mexican American women with polycystic ovary syndrome. Fertility and Sterility 200685 1010-1016.

14 Diamanti-Kandarakis E. PCOS in adolescents. Best Practice $\mathcal{E}$ Research. Clinical Obstetrics \& Gynaecology 201024 173-183.

15 McCartney CR, Prendergast KA, Chhabra S, Eagleson CA, Yoo R, Chang JF, Foster CM \& Marshall J. The association of obesity and hyperandrogenemia during the pubertal transition in girls: obesity as a potential factor in the genesis of postpubertal hyperandrogenesim. Journal of Clinical Endocrinology and Metabolism 200691 1714-1722. 
16 Rosenfield RL. Clinical review: identifying children at risk for polycystic ovary syndrome. Journal of Clinical Endocrinology and Metabolism 200792 787-796.

17 Hannon TS, Janosky J \& Arslanian SA. Longitudinal study of physiologic insulin resistance and metabolic changes of puberty. Pediatric Research 200660 759-763.

18 Caprio S, Plewe G, Diamond MP, Simonson DC, Boulware SD, Sherwin RS \& Tamborlane WV. Increased insulin secretion in puberty: a compensatory response to reductions in insulin sensitivity. Journal of Pediatrics 1989114 963-967.

19 Armengaud JB, Charkaluk ML, Trivin C, Tardy V, Bréart G, Brauner R \& Chalumeau M. Precocious pubarche: distinguishing late-onset congenital adrenal hyperplasia from premature adrenarche. Journal of Clinical Endocrinology and Metabolism 200994 2835-2840.

20 Haroun D, Crocker H, Viner RM, Williams JE, Darch TS, Fewtrell MS, Eaton S \& Wells JC. Validation of BIA in obese children and adolescents and re-evaluation in a longitudinal study. Obesity 200912 2245-2250.

21 Hatch R, Rosenfield R, Kim MH \& Tredway D. Hirsutism: implications, etiology and management. American Journal of Obstetrics and Gynecology 1981140 1291-1307.

22 Brasil AR, Norton RC, Rossetti MB, Leao E \& Mendes RP. C-reactive protein as an indicator of low intensity inflammation in children and adolescents with and without obesity. Journal of Pediatrics 200783 477-480.

23 Matthews DR, Hosker JP, Rudenski AS, Naylor BA, Treacher DF \& Turner RC. Homeostasis model assessment: insulin resistance and beta-cell function from fasting plasma glucose and insulin concentrations in man. Diabetologia $1985 \mathbf{2 8} 412-419$.

24 Lee JM, Okumura JM, Davis MM, Herman WH \& Gurney JG. Prevalence and determinants of insulin resistance among U.S. adolescents. Diabetes Care 200629 2427-2432.

25 Calcaterra V, Klersy C, Muratori T, Telli S, Caramagna C, Scaglia F, Cisternino M \& Larizza D. Prevalence of metabolic syndrome (MS) in children and adolescents with varying degree of obesity. Clinical Endocrinology $2008 \mathbf{6 8} 868-872$.

26 Friedewald WT, Levy RI \& Fredrickson DS. Estimation of the concentration of low density lipoprotein chiolesterol without use of preparative ultracentrifuge. Clinical Chemistry 1972 18 499-502.

27 National High Blood Pressure Education Program Working Group on High Blood Pressure in Children and Adolescents. The Fourth Report on the Diagnosis, Evaluation, and Treatment of High Blood Pressure in Children and Adolescents. Pediatrics 2004114 555-576.

28 Weiss R, Dziura J, Burgert TS, Tamborlane WV, Taksali SE, Yeckel CW, Allen K, Lopes M, Savoye M, Morrison J, Sherwin RS \& Caprio S. Obesity in the metabolic syndrome in children and adolescents. New England Journal of Medicine 2004350 2362-2374.

29 Franks S, Gilling-Smith C, Watson H \& Willis D. Insulin action in normal and polycystic ovary. Endocrinology and Metabolism Clinics of North America $1999 \mathbf{2 8} 361-378$.

30 Rosenfield RL \& Deplewski D. Role of androgens in the developmental biology of the pilosebaceous unit. American Journal of Medicine 199598 80S-88S.

31 Kealey T, Philpott M \& Guy R. Human pilosebaceous culture. Methods in Molecular Biology 199775 101-115.

32 Shah NA, Antoine HJ, Pall M, Taylor KD, Azziz R \& Goodarzi MO. Association of androgen receptor CAG repeat polymorphism and polycystic ovary syndrome. Journal of Clinical Endocrinology and Metabolism 200893 1939-1945.

33 Elting LW, Korsen TJ \& Schoemaker J. Obesity, rather menstrual cycle pattern or follicle cohort size, determines hyperinsulinemia, dyslipidemias and hypertension in ageing women with polycystic syndrome. Clinical Endocrinology 200155 767-776.
34 Fernandes AR, de Sa Rosa de Silva AC, Romao GS, Pata MC \& dos Reis RM. Insulin resistance in adolescents with menstrual irregularities. Journal of Pediatric and Adolescent Gynecology 2005 18 269-274.

35 Cupisti S, Kaiaia N, Dittrich R, Duezenli H, Beckham MW \& Meuller A. Body mass index and ovarian function are associated with endocrine and metabolic abnormalities in women with hyperandrogenemic syndrome. European Journal of Endocrinology 2008158 711-719.

36 De Pergola G, Tartagni M, d'Angelo F, Centoducati C, Guida P \& Giogino R. Abdominal fat accumulation, and not insulin resistance, is associated to oligomenorrhea in non-hyperandrogenic, overweight/obese women. Journal of Endocrinological Investigation 200932 98-101.

37 Korhonen S, Hippelainen M, Vanhala M, Heinon S \& Niskanen I. The androgen sex hormone profile is an essential feature of metabolic syndrome in premenopausal women: a controlled community-based study. Fertility and Sterility $2003 \mathbf{7 9}$ 1327-1334.

38 Valerio G, Licenziati MR, Iannuzzi A, Franzese A, Siani P, Riccardi G \& Rubba P. Insulin resistance and impaired glucose tolerance in obese children and adolescents from Southern Italy. Nutrition, Metabolism, and Cardiovascular Diseases $2006 \mathbf{1 6}$ 279-284.

39 Rossi B, Sukalich S, Droz J, Griffin A, Cook S, Blumkin A, Guzik DS \& Hoeger KM. Prevalence of metabolic syndrome and related characteristics in obese adolescents with and without polycystic ovary syndrome. Journal of Clinical Endocrinology and Metabolism $2008934780-4786$.

40 Caprio S. Insulin resistance in childhood obesity. Journal of Pediatric Endocrinology and Metabolism 200215 (Suppl 1) 487-492.

41 Coviello AD, Legro RS \& Dunaif A. Adolescent girls with polycystic ovary syndrome have an increased risk of metabolic syndrome associated with increasing androgen levels independent of obesity and insulin resistance. Journal of Clinical Endocrinology and Metabolism $200691492-497$.

42 Diamanti-Kandarakis E, Papavassiliou AG, Kandarakis SA \& Chrousos GP. Pathophysiology and types of dyslipidemia in PCOS. Trends in Endocrinology and Metabolism $2007 \mathbf{1 8}$ 280-285.

43 Diamanti-Kandarakis E, Mitrakou A, Raptis S, Tolla G \& Dulleba AJ. The effect of a pure antiandrogen receptor blocker, flutamide, on the lipid profile in the polycystic ovary syndrome. Journal of Clinical Endocrinology and Metabolism $1998 \mathbf{8 3}$ 2699-2705.

44 Shroff R, Syrop CH, Davis W, Van Voorhis BJ \& Dokras A. Risk of metabolic complications in the new PCOS phenotypes based on Rotterdam criteria. Fertility and Sterility $2007 \mathbf{8 8} 1389-1395$.

45 Ladeia AM, Stefanelli E, Ladeia-Frota C, Moreira A, Hiltner A \& Adan L. Association between elevated serum C-reactive protein and triglyceride levels in young subjects with type 1 diabetes. Diabetes Care 200629 424-426.

46 Escobar-Morreale HF, Villuendas G, Botella-Carretero JL, Sancho J \& San Millan JL. Obesity, and not insulin resistance, is the major determinant of serum inflammatory cardiovascular markers in pre-menopausal women. Diabetologia 200346 625-633.

47 Lazzer S, Boirie Y, Meyer M \& Vermorel M. Evaluation of two footto-foot bioelectrical impedance analyses to assess body composition in overweight and obese adolescents. British Journal of Nutrition $200390987-992$.

Received 31 March 2010

Accepted 5 April 2010 